\title{
JOURNAL.RU
}

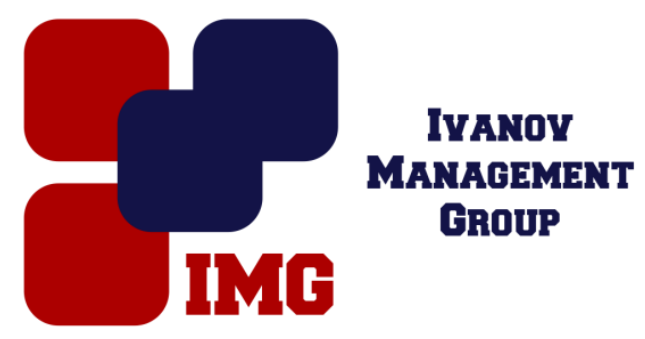

Новиков А.В. ${ }^{1}$, Бурмистров А.В. ${ }^{2}$

${ }^{1}$ ООО Мой капитал

${ }^{2}$ Новосибирский национальный исследовательский государственный университет; Институт вычислительной математики и математической геофизики СО РАН

Новосибирск, Россия

doi: $10.18411 / \mathrm{lj}-31-05-2017-60$

idsp 000001:1j-31-05-2017-60

\section{Виртуальный финансовый консультант, использующий системы искусственного интеллекта и финансовые данные в реальном времени}

\section{Аннотация}

Предлагается разработать интеллектуальную систему, которая способна в автоматическом режиме решать задачу построения эффективных финансовых рекомендаций для решения конкретных персональных финансовых задач, учитывая рыночные условия в каждый конкретный момент времени. Завершается реализация платформы базы данных (хранение, предобработка и систематизация исторических данных о поведении различных финансовых инструментов в прошлом с глубиной более 20 лет). Реализуется получение и обработка в режиме реального времени актуальных финансовых данных. Параллельно, процесс диалогового общения с пользователем находится в стадии тестирования. Разрабатывается блок анализа и обработки больших объемов информации (BigData) для учета новостных лент и другой информации (соцсети, блогосфера и т.д.)в формировании финансовых рекомендаций.

Ключевые слова: автоматизированное консультирование, диалоговое взаимодействие с пользователем, мобильный банк, облачные технологии, искусственные нейросети, большие данные, исторические данные.

\section{Abstract}

We propose to develop an intelligent system that is able to construct automatically the efficient financial recommendations for solving specific personal financial problems. This systemshouldtake into account the market conditions at every particular moment in 
time.The implementation of the database platform (storage, preprocessing and systematization of historical data on the behavior of various financial instruments in the past with a depth of more than 20 years) is coming to the end. We implement the retrieval and processing in real time of actual financial data .In parallel, the process of conversation with the useris in the testing phase. We developa block of analysis and processing of Big Data to take into account the news services and other information (social networks, blogosphere, etc.) for generating the financial recommendations.

Keywords: robo advising, conversationwith the user, mobile banking, cloud technologies,artificial neural networks, BigData, historical data.

\section{Введение}

Рассмотрим две основные существующие проблемы в области оказания финансовых услуг населению.

1. Потребность замены продавцов на высокотехнологичные решения. «Технология вместо продавцов» сейчас нужна финансовому сектору [18], поскольку на рынке востребованы финансовые консультанты, дающие персональные рекомендации конкретному пользователю. Для человека-консультанта всегда есть вероятность принятия ошибочных или алогичных решений в конкретных ситуациях, и это является проблемой практически всех финансовых организаций. Решение проблемы заключается в автоматизации процесса консультирования и наша платформа предоставляет полный цикл, то есть она способна реально помочь людям эффективнее инвестировать свои сбережения.

2. Миграция пользователей финансовых услуг на смартфоны. На данный момент у большинства финансовых организаций наблюдается одна общая проблема: они стараются донести до потребителя свои коммерческие предложения устаревшими на данный момент методами (холодные звонки, вебсайты, смс-рассылки и т.д.), однако это, как правило, неэффективно, поскольку их коммерческие предложения часто непонятны и неудобны конечному пользователю. Особенно это относится к представителям молодого поколения (поколение Z), для которого графическая информация воспринимается лучше текста, а средний период концентрации не превышает 10 секунд [9]. Если раньше клиенты пользовались интернетом, затем мобильным интернетом, то на текущий момент тренд смещается в сторону использования мобильных ИТ продуктов[10-13]. Целевая аудитория 
большинства финансовых организаций - это активные пользователи. Они изначально мотивированы устанавливать и использовать интересные им приложения, поэтому они переходят на смартфоны и другие мобильные устройства. Фактически данная категория пользователей готова использовать только продукт с ИТ технологиями доступными в магазинах мобильных приложений (AppleStore, GooglePlay, WindowsStore). Наша платформа решает эту проблему путем создания экосистемы понятных и удобных мобильных приложений для того, чтобы пользователь сам выбирал наиболее подходящие именно ему.

\section{Предлагаемое решение}

Мы предлагаем создать платформу виртуального финансового консультанта. Дата центр созданной платформы будет построен на облачных технологиях.

Инновационность нашей системы заключается в независимости от человеческого фактора - весь процесс (от диалога пользователь-система до выдачи области возможных решений или ближайших решений к запросу) полностью автоматизирован (см. Рис.1). В тот момент, когда в силу вступит закон, позволяющий гражданам РФ выполнять открытие банковских депозитов, брокерских счетов онлайн, и когда это практических будет возможно удаленно через систему госуслуг (ЕСИА), наша платформа заработает полностью в режиме автоматизированной системы. Ее преимуществами являются: возможность обновления и улучшения отдельных блоков и системы целиком; возможность итерационного развития, а в случае необходимости возможность отмены внесенных изменений (откат системы до стабильной версии). Кроме того, система будет доступна круглосуточно в режиме 24/7/365. 


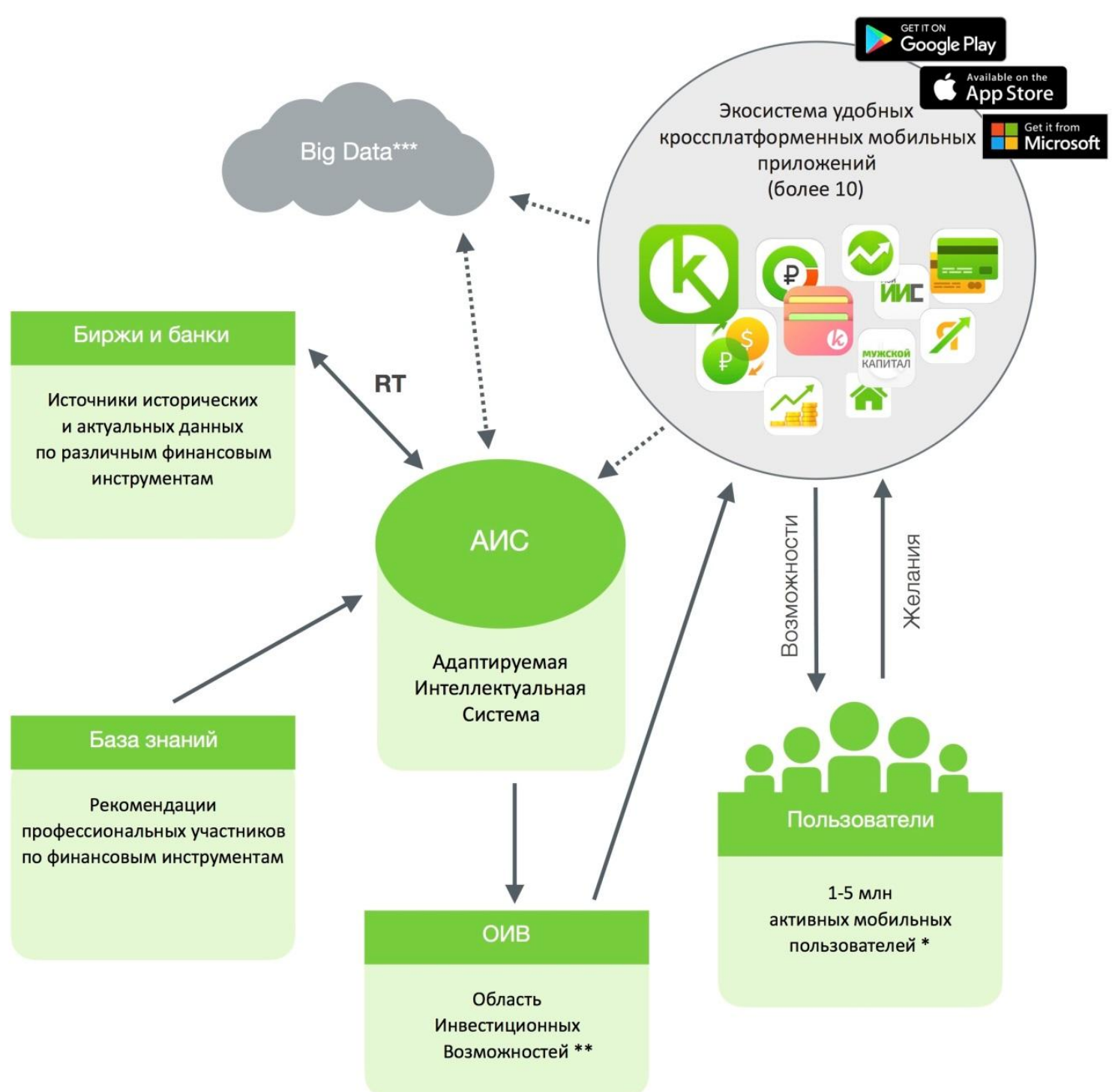

Рисунок 1. Схема платформы «Технология вместо продавиов» (сплошная линия - реализованный функиионал, пунктирная линия - в процессе разработки) * 1 млн. пользователей на начало 2018 года, 5 млн. - на начало 2020 года.

** ОИВ является максимально персонализированной.

*** В данньй момент BigData собирается и достигнет необходимого для работь объема к кониу 2017 года.

На первом этапе пользователь будет вести диалог с нейросетевой надстройкой приложения (см. Рис.2), в ходе которого будет собрана необходимая информация о потребителе. При этом будут определены 5 базовых параметров: потенциальные сумма и срок инвестирования, ожидаемая доходность и приемлемый риск, а также ликвидность. Затем по первым двум параметрам адаптируемая интеллектуальная система (АИС) в режиме реального времени строит область инвестиционных возможностей (ОИВ) - 3D визуализацию практических рекомендаций пользователю по его финансовой стратегии поведения (см. Рис.3). При этом используются стохастические модели цен и соответствующие алгоритмы их прогноза [14-18]. ОИВ строится в координатах доходность-риск для набора различных финансовых инструментов: 
государственные ценные бумаги, акции, облигации, депозиты, индивидуальные инвестиционные счета (ИИС), паевые инвестиционные фонды (ПИФ), валюта. Если запрос пользователя попадает в ОИВ, то такой запрос признается «адекватным» и пользователю предлагается спектр решений. В противном случае запрос пользователя признается «неадекватным», и система предлагает пользователю инвестиционные возможности из ОИВ, наиболее близкие к его запросу.
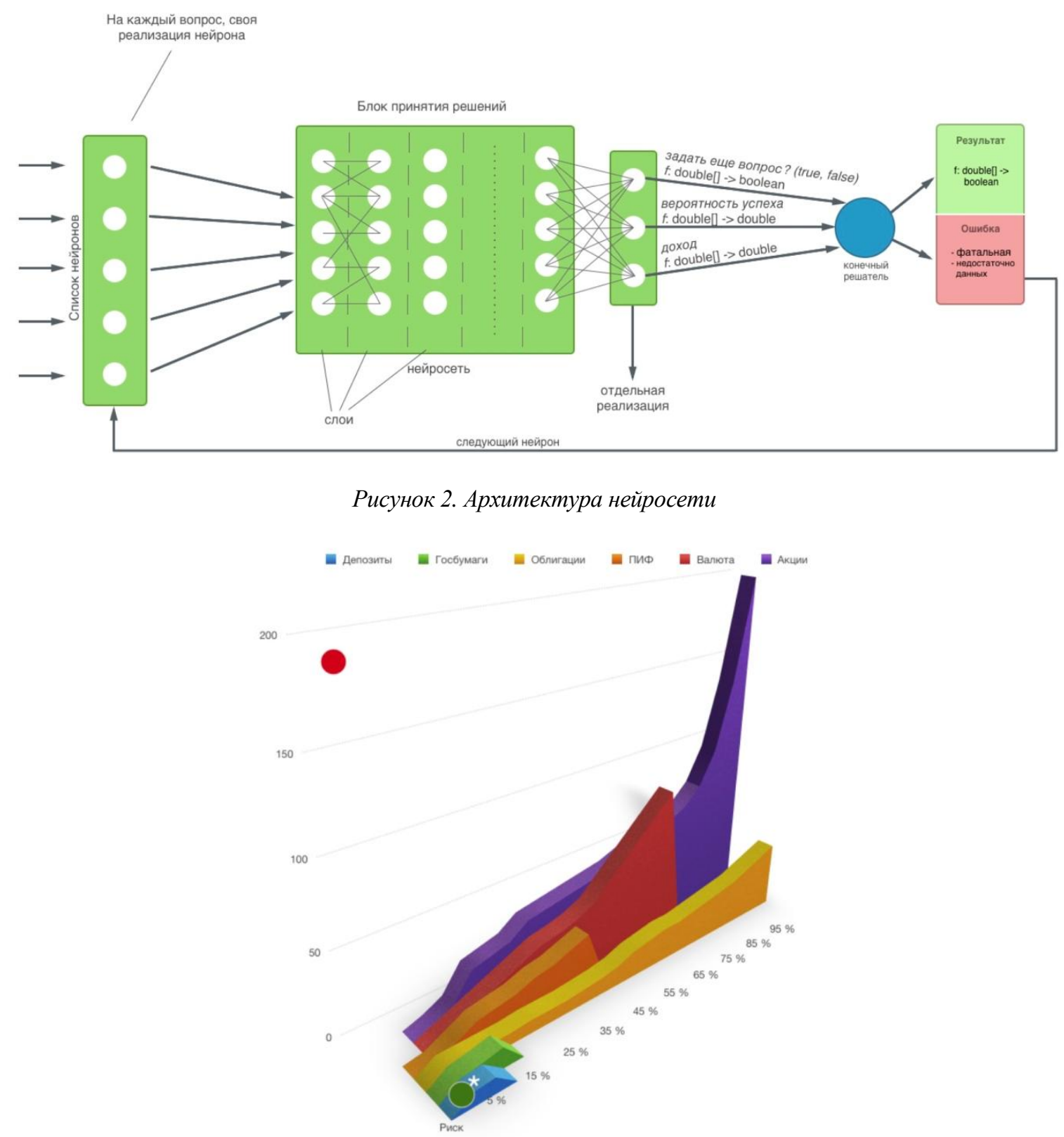

Рисунок 3. Пример ОИВ. Сумма инвестиций от 10 млн.руб. (красная точка - неадекватньй запрос, зеленая точкаадекватный запрос)

* Такая доходность и риски возможны при условии разбиения суммы по депозитам разных банков в сумме до 1,4 млн.руб. на каждый отдельный депозит.

Отдельно отметим, что ОИВ предлагает оптимальные для пользователя финансовые инструменты не в рамках одной компании или группы компаний, а в 
рамках финансового рынка в целом, что также отражает инновационность нашего подхода.

\section{Основные направления монетизации}

1. Разработка собственной платформы персонального виртуального финансового консультирования пользователей и дистанционной продажи финансовых продуктов от различных финансовых организаций для стран СНГ и азиатского региона для мобильных устройств, работающих на операционных системах iOS, MacOS, Android, Windows.

Платформа для каждого региона (страны) будет состоять из более чем 10 мобильных приложений, которые составят единую экосистему. Собранные через эту экосистему персональные пожелания активных мобильных пользователей (в том числе плохо знакомых с финансовой сферой) обрабатываются АИС в режиме реального времени на основе актуальных финансовых данных и в результате каждый пользователь получает индивидуальную область инвестиционных возможностей (ОИВ). Монетизация платформы будет осуществляться за счет агентского вознаграждения от финансовых организаций за услуги по моделям CPL (costperlead), CPA (costperaction). Вознаграждение применяется в зависимости от финансового продукта и тарифных условий.

2. Разработка на основе адаптируемой интеллектуальной системы (АИС) облачного сервиса по модели $\mathrm{SaaS}$ (softwareas a service) для финансовых организаций, формирующего персонализированные рекомендации в области финансовых решений для стран СНГ и азиатского региона.

Такой облачный сервис, используя API для автоматизированного обмена данными, позволит финансовым учреждениям без особых затрат интегрировать возможности АИС в собственные сервисы и системы, как в области консультирования, так и в области прогнозирования и планирования. Широкая применимость нашего сервиса в различного рода задачах финансовой сферы хорошо коррелирует с масштабируемостью и невысокой стоимостью интеграции облачного решения. Вознаграждение в этом случае будет поступать от финансовых организаций и других заинтересованных пользователей в виде арендных платежей за пользование системой, через систему подписок.

3. Выпуск и продажа совместно с финансовыми организациями финансовых продуктов, обладающих высокими потребительскими качествами в области текущих инвестиционных возможностей.

Собранный массив данных о персональных пожеланиях пользователей 
системы позволит оценить точки высокого спроса для текущего момента времени и совместно с различными финансовыми организациями оперативно выпускать специальные финансовые продукты под этот спрос. Точное понимание реальных потребностей пользователей системы позволит эффективно разработать не только сам продукт, но и подобрать наиболее подходящую для этого спроса финансовую организацию эмитента. Оперативность получаемых данных дает возможность своевременно предоставить на финансовый рынок такие продукты. Вознаграждение планируется получать от долевого участия в доходах от размещения разработанных финансовых продуктов.

\section{Перспективы рынка}

Разрабатываемый продукт относится к рынкам Робо-консультирования (Robo-Advising) и Виртуальных цифровых помощников (VDA VirtualDigitalAssistant)[19-23].

Robo-Advising- объем глобального рынка пользователей робоконсультантов вырастет до 90 млн. человек к 2021 году и до 16 трлн. долларов под управлением.

VDA - объем глобального рынка пользователей виртуальных цифровых помощников вырастет с 390 млн. в 2015 до 1,8 млрд. человек в 2021 и выручки до 16 млрд. долларов.

На этих рынках компания Мой Капитал ориентирована на вертикальные рынки: розничный банкинг, инвестиции, страхование с целью занять долю более $5 \%$ в России и СНГ и до 1,5\% в регионах: Юго-Восточная Азия, Ближний Восток, западная Европа к 2019 году.

У нашего продукта существует два профиля клиентов:

- b2c частные пользователи устанавливающие приложение напрямую из магазинов приложений;

- b2b корпорации (банки, брокеры, страховые компании) использующие платформу Мой Капитал для использования в собственных приложениях и интерфейсах.

Горизонтальные рынки: онлайн продажи (sales), клиентская поддержка (support), вовлечение и удержание клиентов (engagementandretention).

Демографические рынки: поколения Z и Y.

\section{Заключение}

В заключение отметим преимущества нашей платформы: 
1) Разработка системы поддержки принятия решений о финансовых продуктах является ключевым фокусом проекта в отличие от конкурирующих решений.

2) Скорость и гибкость разработки, а также использование микросервисной архитектуры платформы дает временное преимущество перед крупными компаниями.

3) «Мой Капитал» обладает собственной экосистемой приложений для востребованных финансовых потребностей пользователей: в магазинах мобильных приложений (AppleStore, GooglePlay, WindowsStore) уже размещены более 10 наших мобильных приложений. Соответственно, наша компания самодостаточна в отношении необходимого для обучения собственных алгоритмов объема данных.

В момент практической реализации закона о возможности открытия банковских счетов (депозитов, пластиковых карт), а также брокерских счетов удалено через ЕСИА (госуслуги) наша система заработает в полностью автоматизированном в режиме. 
1. Лучшие зарубежные Робо-эдвайзеры - изучаем что предлагают инвесткомпании [Электронный ресурс]. - Режим доступа: http://iis24.ru/best-foreign-robo-advisors-in2016/, свободный. - (Дата обращения: 23.05.2017).

2. Роботы-консультанты добрались до России [Электронный ресурс]. - Режим доступа: https://www.vedomosti.ru/finance/articles/2016/07/15/649324-roboti-konsultanti-dobralisrossii, свободный. - (Дата обращения: 23.05.2017).

3. Роботы-консультанты могут занять $10 \%$ рынка управления активами [Электронный pecypc]. - Режим доступа: http://www.finanz.ru/novosti/lichnyye-finansy/robotykonsultanty-mogut-zanyat-10percent-rynka-upravleniya-aktivami-1001061753, свободный. - (Дата обращения: 23.05.2017).

4. MrRobot, yournewfinancialadviser [Электронный pecypc]. - Режим доступа: https://www.ft.com/content/48e5f1a0-d631-11e5-829b-8564e7528e54, платный. - (Дата обращения: 23.05.2017).

5. Совет да доход: так ли опасны робо-эдвайзинг и системы автоследования [Электронный ресурс]. - Режим доступа: https://fomag.ru/news/sovet-da-dokhod-tak-liopasny-robo-edvayzing-i-sistemy-avtosledovaniya/, свободный. - (Дата обращения: 23.05.2017).

6. ЦБ считает преждевременным лицензирование робо-эдвайзинга [Электронный ресурс]. - Режим доступа: https:/fomag.ru/news/tsb-schitaet-prezhdevremennym-litsenzirovanierobo-edvayzinga/, свободный. - (Дата обращения: 23.05.2017).

7. Робо-эдвайзинг, или не разорит ли нас компьютерный интеллект [Электронный pecypc]. - Режим доступа: https://fomag.ru/news/robo-edvayzing-ili-ne-razorit-li-naskompyuternyy-intellekt/, свободный. - (Дата обращения: 23.05.2017).

8. Банк России опасается роботов-консультантов [Электронный ресурс]. - Режим доступа: https://fomag.ru/news/bank-rossii-opasaetsya-robotov-konsultantov/, свободный. (Дата обращения: 23.05.2017).

9. 30 фактов о современной молодежи [Электронный ресурс]. - Режим доступа: http://www.sberbank.ru/common/img/uploaded/files/pdf/youth_presentation.pdf, свободный. - (Дата обращения: 23.05.2017).

10. Десктоп, посторонись! Как мобильные платежи формируют покупательские привычки пользователей [Электронный ресурс]. - Режим доступа: http://www.forbes.ru/tehnologii/341877-desktop-postoronis-kak-mobilnye-platezhiformiruyut-pokupatelskie-privychki, свободный. - (Дата обращения: 23.05.2017).

11. Мобильный банкинг для смартфонов [Электронный ресурс]. - Режим доступа: https://www2.deloitte.com/ru/ru/pages/financial-services/articles/mobile-banking.html, свободный. - (Дата обращения: 23.05.2017).

12. 28\% пользователей выбирает мобильные аккаунты для совершения онлайн-транзакций [Электронный ресурс]. - Режим доступа: https://iot.ru/riteyl/28-polzovateley-vybiraetmobilnye-akkaunty-dlya-soversheniya-onlayn-tranzaktsiy, свободный. - (Дата обращения: 23.05.2017).

13. Как будут выглядеть банки будущего [Электронный ресурс]. - Режим доступа: https://apparat.cc/world/banks-of-the-future/, свободный. - (Дата обращения: 23.05.2017).

14. Новиков А.В., Бурмистров А.В. Моделирование ценового ряда в рамках стохастической дифференциальной модели // Международный научный журнал "Символ науки". 2017. №04-2. С.17-21. 
15. Коротченко М.А., Бурмистров А.В. Моделирование динамики многочастичных ансамблей при использовании кинетических моделей // Образовательные ресурсы и технологии. 2016. № 2 (14). С. 324-330.

16. Новиков А.В. Адаптированные стохастические дифференциальные модели ценового ряда. Препринт ИВМиМГ СО РАН, 1157. Новосибирск, 2003. 26стр.

17. Artemiev S.S., Novikov A.V., Ogorodnikov V.A. Mathematical aspects of computer-aided share trading // Russian Journal of Numerical Analysis and Mathematical Modelling. 2002. V. 17. No. 4. P. 331-346.

18. Бурмистров A.В., Коротченко М.A., Reisswich М. Моделирование цены методом Монте-Карло в рамках модели больцмановского типа // Материалы XVII Всероссийской конференции молодых ученых по математическому моделированию и информационным технологиям. Новосибирск, Россия. 30 октября - 3 ноября 2016 г., стр.29.

19. Conversational Banking Will Transform the Financial Services Industry [Электронныйресурс]. Режимдоступа: https://thefinancialbrand.com/63772/conversational-banking-chatbots-bots-ai-messaging/, свободный. - (Датаобращения: 23.05.2017).

20. Size of the enterprise virtual digital assistant (VDA) market worldwide from 2015 to 2021 (in million U.S. dollars) [Электронныйресурс]. - Режимдоступа: https://www.statista.com/statistics/589068/worldwide-virtual-digital-assistants-enterprisemarket/, свободный. - (Датаобращения: 23.05.2017).

21. Robo-Advisors[Электронный pecypc]. https://www.statista.com/outlook/337/100/robo-advisors/worldwide, платный. - (Дата обращения: 23.05.2017).

22. Virtual Digital Assistants: Virtual Agents, Chatbots and Virtual Assistants for Consumer and Enterprise Markets [Электронныйресурс]. http://www.researchandmarkets.com/reports/3796087/virtual-digital-assistants-virtual-agents, платный. - (Датаобращения: 23.05.2017).

23. The robo advising report: Market forecasts, key growth drivers, and how automated asset management will change the advisory industry [Электронныйресурс]. - Режимдоступа: http://www.businessinsider.com/the-robo-advising-report-market-forecasts-key-growthdrivers-and-how-automated-asset-management-will-change-the-advisory-industry-2016-6, платный. - (Датаобращения: 23.05.2017). 